\title{
LA FILOLOGÍA Y LOS FILÓLOGOS
}

\author{
Carmen Codoner Merino*
}

RESÚMEN: El texto que sigue es la transcripción de una clase inaugural de la Universidad de Salamanca, para el año escolar de 2004-2005. Fue pronunciado en septiembre de 2004, en solemnidad tenida en un edificio histórico de aquella Universidad, un palacio magnífico del siglo XII. La autora, Carmen Codoner Merino es catedrática de aquella institución y una autoridad en filología clásica. Autora de numerosos estudios críticos sobre textos medievales y renacentistas, además de ensayos monográficos sobe Séneca y Tácito, Carmen actualmente tiene particular interés en la transmisión y recepción de estos textos, enfatizando la etimología léxica como un modo de aproximarse de los contextos socio-político y literario en el momento que fueron escritos. Ella todavía enfatiza la importancia de la gramática en la historia de la educación. la clase que sigue, con su erudición y notable fluidez narrativa es una pequeña muestra de su enorme y rico dominio de investigación. Educación y Sociedad está orgullosa de ofrecer esta transcripción a sus lectores y está segura de que ellos están contentos en recibirla. Esta iniciativa es parte de la intención de destacar el intercambio con aquella importante Universidad y con las reflexiones sobre educación que se producen en aquel País.

Palabras clave: Filología. Recepción de texto. Léxico. Etimología. Gramática e historia.

\section{THE PHILOLOGY AND THE PHILOLOGISTS}

ABSTRACT: The text that follows is the transcription of an inaugural class at the University of Salamanca, for the 2004-2005 scholar year. It was addressed in September 2004, in solemnity held in the historical building of that University, a magnificent palace from the XII Century. The author, Carmen Codoner Merino is professor of that institution and an authority in classical philology. Author of

\footnotetext{
* Professora titular de filologia clássica da Universidade de Salamanca (Espanha). E-mail: codo@usal.es
} 
numerous critical studies on medieval and renaissancist texts, besides monographic essays on Sêneca and Tácito, Carmen currently has particular interest in transmission and reception of these texts, emphasizing the lexical etymology as a way to come close to the socio-political and literary contexts by the time they were written. She still emphasizes the importance of the grammar in the history of education. The class that follows, with her erudition and notable narrative fluency, is a small example of the enormous and rich dominion of research. Educação \& Sociedade is proud to offer this transcription to their readers and is quite sure that they are pleased to receive it. This initiative is part of the purpose to emphasize the interchange with that important University and with reflections on educational methods that are produced in that country.

Key words: Filology. Reception of the text. Lexical. Etymology. Grammar and history.

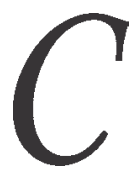

ostumbres y tradiciones, tomando tradición en su acepción de ceremonial, no son equivalentes. Nadie puede pensar en poner fecha de inicio a una costumbre, como tampoco depende de la voluntad de los seres humanos el erradicarla de golpe. Las costumbres se van transformando, se adaptan de modo insensible a los cambios de situación. Suelen mantener vivas las razones por las que se originaron $y$, al contrario que la tradición, admiten cambios en la superficie que no afectan sustancialmente al fondo. Su desaparición, cuando así sucede, pasa desapercibida porque se da al final de un largo y paulatino proceso de adaptación. Más que de desaparición, en realidad, podría hablarse de transformación, de sustitución. La modificación de una costumbre marcha al mismo ritmo que los cambios sociales, porque es una manifestación externa de éstos. Por esa razón, una costumbre perdida en su forma originaria es irrecuperable.

No sucede lo mismo con la tradición. La tradición es inflexible, se quiebra o desaparece, no se modifica, tal vez porque su existencia está ligada a la forma, no va más allá de ella. Por ejemplo, esta ceremonia responde a una creación consciente y nada impide que en un momento dado se le ponga fin. Con su supresión no tiene por qué cambiar nada en lo sustancial, porque la tradición no interfiere en el desarrollo de las instituciones, su existencia no está ligada a su evolución, es un "monstruo" cuya vida depende de la voluntad del hombre. La desaparición de una tradición supone una pretendida 
ruptura con el pasado, sin repercusión social en la mayoría de las ocasiones. Si las tradiciones se mantienen, así puede interpretarse, es como simbólicos homenajes a un pasado del que procedemos, nos guste o no ese pasado. Mantenerlas significa, en mi opinión, aceptar ese pasado del que nosotros somos una consecuencia. La interpretación del pasado es una cuestión personal, el recuerdo - por ser necesario - no debiera quedar en manos de los individuos. La memoria es necesaria porque el olvido es peligroso.

El rechazo de esta ceremonia, como símbolo que es de la voluntad de cada momento, implica el rechazo a las instituciones, en la medida en que éstas no responden a las exigencias que el colectivo universitario exige. $\mathrm{Y}$ es cierto que, en circunstancias concretas, la eliminación de un ceremonial ha podido adquirir el carácter simbólico de cambio. Pensamos que acabando con ellas estamos dando paso a un nuevo modelo de sociedad, pero también es cierto que, puesto que ceremonias y tradiciones son forma, su eliminación necesita ir acompañada de un cambio en el objeto que simbolizan. Esta ceremonia sólo recubre la realidad de una institución que, a su vez, es reflejo de la sociedad en la que se inserta, pero no influye sobre ella.

No se elige el país en que se nace, ni la sociedad del momento. La historia de la universidad de un país es la de ese país y a convivir con el pasado lejano, y no tan lejano, se aprende con esfuerzo. Se aprende a aceptar convenciones y ritos no dañinos y a rechazar lo nocivo. Se aprende a prescindir de aquello que es inútil e impide avanzar y a conservar lo que no es útil, pero representativo. Probablemente hace más de 30 años, incluso menos, yo no hubiera aceptado estar aquí, no entro en si equivocadamente o no, porque esta ceremonia tenía y sigue teniendo un valor simbólico. En estos momentos, ya tan distintos, mi presencia aquí la valoro en lo que para mí significa: representar a mi facultad y, más en concreto, a mi departamento y a mi especialidad de filología latina, continuando una tradición centenaria.

Quisiera que mi intervención fuera un homenaje a esta tradición y, con ello, dando un paso más allá, contribuir a la recuperación de la memoria real, no siempre grata. Precisamente por ser un residuo del pasado, en ocasiones muy alejado de nosotros, las razones sobre las que se basó su creación ya nadie las recuerda. Como inicio de esta intervención quisiera recoger, a modo de apunte, una escueta información sobre sus orígenes. 


\section{Las orationes inaugurales de curso académico}

La creación de las universidades es algo lejano. Las ceremonias con las que se fue dando forma a su existencia no surgieron todas simultáneamente, sino que se fueron escalonando con el paso del tiempo. Me gustaría pensar que, con esta ceremonia de inauguración de curso, sus iniciadores quisieron insistir sobre la necesaria renovación de la institución, quisieron recordar a la comunidad universitaria que cada nuevo curso no es una simple continuación del anterior, que todos los años la institución, y quienes la conforman, deben abrir un nuevo capítulo de una pequeña historia personal y una gran historia colectiva. No siempre los deseos coinciden con la realidad y no creo que ésta sea precisamente la interpretación más adecuada, pero al menos es esperanzadora.

La universidad fue incorporando a su ceremonial, desde sus orígenes, una serie de actos fijos: inauguración de curso, incorporación al claustro de la academia de nuevos profesores, comienzo de los respectivos cursos. Se han conservado presentaciones a cursos concretos, que son pequeños tratados de gran validez para el momento. ${ }^{1}$ Todos son comienzos que merecen ser registrados oficialmente con actos especiales.

De distinta manera hay que considerar otros actos, obligatorios para el profesorado, como son las repetitiones, especie de lección magistral anual en la que el profesor desarrollaba un punto concreto de la materia que impartía, aportando novedades y avances al tema escogido. Algunas de estas repetitiones suponen un avance real en el conocimiento de una rama concreta de la ciencia, pero esto no ayudó a que la norma cuajara en tradición, tal vez por una relajación en su cumplimiento. ${ }^{2}$

Como corresponde a la importancia concedida a los inicios del curso, la oratio inauguralis era la más destacada y de ella se encargaba el profesor al que correspondía, de acuerdo con un turno establecido. La importancia del resto iba normalmente vinculada a la valía del profesor que la pronunciaba. El discurso de inauguración se pronunciaba el 18 de octubre, día de San Lucas, fecha que poco a poco fue aceptada por casi todas las universidades para el comienzo de la docencia. ${ }^{3}$ El tema no era libre, se ajustaba a directrices precisas. Dirigida como estaba a autoridades académicas y civiles, a profesores, estudiantes y a un público ciudadano, debía centrarse en la alabanza y utilidad de los es- 
tudios que se realizaban en la universidad, por lo general siempre los mismos: artes, medicina, derecho civil y canónico y teología. ${ }^{4}$ Asimismo debía incluir una exhortación a los estudiantes para que aprovechasen las oportunidades de formación que ante ellos se abrían.

Naturalmente, dentro de la forma de discurso impuesta, era imprescindible introducir una serie de tópicos, algunos en uso todavía, otros en desuso. Era habitual comenzar con una loa de las autoridades que asistían al acto y una loa del profesor que había pronunciado la oratio el curso anterior o anteriores. Imprescindible era el agradecimiento por haber sido elegido para circunstancia tan importante, tópico que, en lógico encadenamiento, iba acompañado del reconocimiento de la incapacidad para desempeñar dignamente papel tan importante.

La necesidad de la oratio de atenerse a una norma explícita: inserción de una laus litterarum, y a normas no escritas, pero igualmente respetadas, como las que acabo de mencionar, podría inducir a pensar en la semejanza, casi identidad, de todos los discursos. ${ }^{5}$ Una lectura superficial así parece indicarlo, pero en cada discurso existen matices propios que lo enlazan con las circunstancias de su momento y de su localización geográfica. El hecho queda claro si comparamos discursos inaugurales de un mismo periodo correspondientes a países distintos, con problemas distintos.

Un caso servirá para ilustrar lo anterior. Los discursos de Juan de Brocar (1520), Lope de Herrera (1520) y Juan Pérez (1537), fueron pronunciados en Alcalá de Henares y el de Juan de Maldonado sirvió para abrir el curso académico 1545-1546 en Burgos. Los cuatro comparten los tópicos, aunque introducen elementos propios que los diferencian, les dan tonalidad distinta. Al mismo tiempo, el hecho de compartir un arco de tiempo semejante y ser hispánicos los aúna en una preocupación común: la orientación y aceptación o rechazo de unos estudios universitarios que suponen una alta valoración de la formación humana del estudiante. ${ }^{6}$ Juan de Maldonado, por boca de un discípulo, revela su sentir ante la hostilidad por parte de algunos (parece que numerosos) eruditi ante la formación que se imparte en la universidad. La misma situación que encontramos en Juan de Brocar y que se ha puesto en relación con la reacción ante la influencia erasmista. La desconfianza natural hispánica ante los hombres de letras se ve acentuada con el problema erasmista, que lleva a límites insospechados los excesos de la ortodoxia religiosa. ${ }^{7}$ Todos ellos 
aluden a la situación, unos indirectamente, otros sumergiéndose en una defensa a ultranza de la formación encaminada a fines más altos que los propiamente humanos, como es el caso de Lope de Herrera.

La lectura de algunos discursos de este género italianos del siglo $\mathrm{XV}$ nos da un toque peculiar. En todos ellos encontramos una loa concreta a la ciudad sede del estudio en que se está hablando y al protector de la esa ciudad y de sus estudios, quien los defiende y atrae a los mejores profesores. En algunos casos el protector a quien se exalta es un Papa, tal como suced en el caso de Valla en Roma, con Calixto III. Situaciones distintas, que exigen la atención a puntos distintos.

\section{La laus litterarum}

\subsection{La filología}

Común a todos los discursos de comienzo de curso era una loa de todas las especialidades que se cultivaban en la universidad correspondiente, incidiendo, como es natural, en aquella profesada por el encargado del discurso.

A nadie puede caber la duda de que la realidad de nuestras universidades actuales impide realizar un ejercicio consistente en una loa de todas y cada una de las materias que abocan a las especialidades integradas en la universidad. Tampoco se trata de hacer una defensa a ultranza de mi especialidad, actitud que acaba por confundirse con la arrogancia o menosprecio a todo el resto. Y, a pesar de todo, voy a intentar atenerme a la tradición; quisiera con mi discurso recuperar la existencia de esa desconocida que ha dado nombre a la facultad en donde desempeño mi labor: la filología.

No voy a hacer una historia de la filología, cosa que puede encontrarse en un buen manual, sólo intentaré explicar en que consiste actualmente la filología, exponer, con toda la claridad de que soy capaz, a qué nos dedicamos para que, al menos, sea el conocimiento de nuestra labor el que lleve a otorgarle una valoración u otra.

Me pregunto con frecuencia, cuántos, entre ese gran número de personas que constituye la universidad e incluyendo a aquellos que año tras año deciden matricularse en ella, se han parado a pensar cuál es el objeto de la filología. Acostumbrados a esta denominación, tras 
ella sigue viéndose la consabida asimilación con aquel antiguo letras que acompañaba a filosofía. Tiendo a pensar que, en el mejor de los casos, es decir, si se produce esa reflexión, la relación se establece con la lengua y la literatura, dando así por salvado un obstáculo aparente. Claro que hay siempre gente curiosa, en el sentido real que tuvo la palabra en su momento, que se preocupa por cuestiones que quedan fuera de su ámbito, pero ahora me estoy refiriendo a una mayoría que, en términos electorales, podríamos llamar absoluta. La filología tiene una larga tradición y merece una aclaración en un círculo más amplio que aquél al que estamos acostumbrados a dirigirnos. Un círculo, además, de personas dispuestas y capaces de captar nuestras palabras.

La identificación con letras conduce de inmediato a aceptar nuestra existencia bajo los presupuestos tradicionales: un pueblo civilizado y desarrollado, como lo es el nuestro, debe contar entre sus ciudadanos con gente capaz de transmitir una cultura de un nivel digno. Nosotros vendríamos a ser los preparadores de los futuros profesores de lengua y literatura en la enseñanza media. Profesores de lengua y literatura española, francesa, inglesa, italiana... incluso de latín y griego en un exceso de comprensión. Nosotros los encargados de velar por la elegancia de la expresión y la formación literaria, los conocedores de las historias de las lenguas, de las historias de sus literaturas.

Lo que ya no resulta tan claro es el proceso que en filología se sigue, o debe seguirse, en la transmisión de conocimientos, cuál es la formación que se pretende. Porque de la facultad de filología no sólo proceden los profesores de enseñanzas medias, de cuya competencia y esfuerzo tanto depende el futuro, sino también los profesores de universidad que junto a la función docente, como el resto de quienes imparten materias "científicas", deben desarrollar una actividad investigadora. Sin ella, la docencia carece de sentido, se transforma en rutina, queda desfasada. Para transmitir cualquier tipo de conocimientos hay que tener una preparación en profundidad que sólo se adquiere con la actividad investigadora. Tal vez el punto obscuro de la profesión que hemos elegido radique ahí: comprender la finalidad de la filología, el objeto del que se ocupa y el método utilizado en el proceso seguido.

Para empezar, no hay que olvidar que nuestra facultad, bajo la misma etiqueta de filología, da cabida a especialistas de literatura y lingüística, cuyo punto de convergencia no es otro que su común formación filológica. Un único elemento procura la comunidad de ambas 
ramas: el texto, entendiendo por tal tanto el texto escrito como el oral. Para nosotros, en cuanto científicos, la literatura, la lengua, es percibida como texto. Nuestra apreciación personal se superpone, mejor dicho, se sustenta sobre el análisis del texto. El texto es el objeto, un objeto inmaterial, pero caduco, un objeto irrepetible, condiciones todas, en especial la última, que complican las posibilidades de contrastar las conclusiones obtenidas a partir de su estudio.

Los resultados del ejercicio de una misma lengua en situaciones similares, sometida al mismo tipo de condicionamientos externos, orientados a una misma finalidad, son siempre distintos. Todo discurso escrito u oral es único. La filología no pretende dar una explicación al texto (esa es tarea del crítico literario que, por principio, debe ser filólogo), sino una explicación del texto. Desentrañar todos los elementos contextuales que han hecho del texto lo que es, internos y externos: lingüísticos y retóricos; materiales, históricos, sociales, culturales, lingüísticos, retóricos... Cómo y cuándo se ha generado, cómo ha llegado a nosotros, cómo ha sido apreciado en cada etapa de su transmisión... Éste es el objeto de la filología, que con ello busca contribuir a profundizar en la percepción de una época.

Quedan lejos aquellos momentos en que un mismo estudioso pretendía - y, a veces, lo lograba - abarcar todo ese mundo de conocimientos. Podemos encontrar huellas de los recelos suscitados en el resto de los profesionales, ya a finales del siglo XV y principios del XVI, en las voces de los italianos y también de los españoles. ${ }^{8}$ El filólogo actual está forzado a ser modesto, necesita ayuda, ayuda que encontramos en las consultas con personas de distintas especialidades y, cómo no, en nuestro instrumento básico de trabajo: las bibliotecas, particular laboratorio que no admite sustituciones por deterioro o desuso y que, por el contrario, procede por acumulación. En filología un libro de principios del siglo XX puede tener validez para el investigador; el valor de los libros no se mide por la fecha más o menos reciente de aparición, sino por la calidad. Ciertamente los avances en el método permiten progresar, pero siempre contando con el pasado como punto de referencia.

\subsection{El texto}

Metafóricamente puede hablarse de la vida de un texto, en la misma medida en que decimos que un texto está vivo. Se habla de la 
vigencia literaria de una obra de manera parecida a como decimos que una persona sigue viva mientras hay gente viva que la mantiene en su recuerdo. En ambos casos la vida depende de los hombres que recuerdan o de los hombres que leen. Sin embargo, hay una diferencia fundamental: las personas recordadas están incorporadas a la historia de quien las recuerda, la obra literaria cuenta con un texto al que acompaña una historia propia, independiente del lector. La idea de hacer que cada hombre retenga un libro de memoria, en el caso de que el mundo tuviera intención de acabar con los libros, acabaría al mismo tiempo con la lectura filológica, porque dejaría a los textos sin historia. La filología es inconcebible sin la historia del texto.

Hay varios modos de leer un texto; el modo literario aprecia el texto en sí mismo, en su belleza, que se corresponde con el uso de la lengua, con la estructura de la narración, con lo que sugiere y recrea. Ese mismo texto leído con una finalidad filológica adquiere otros contornos que no le restan belleza, sino que la hacen comprensible, la explican en su momento de creación. Es difícil que un filólogo, incluso cuando lee un texto literario sin otro objetivo que el puro deleite, deje de preguntarse e interesarse por el momento en que se escribió, las circunstancias que le dieron origen o las tendencias literarias del momento de escritura. Eso no le impide disfrutar; la diferencia, derivada de vicios de oficio, está en la dirección que adopta el disfrute. Un buen crítico literario, aun sin ser consciente de ello, es en el fondo un buen filólogo o, al menos, podría llegar a serlo.

La actividad del filólogo, en cierto modo, se ve obligada a moverse en un círculo vicioso, cuya complejidad aumenta a medida que la distancia que lo separa del texto que estudia es mayor. Para analizar el texto es conveniente conocer las circunstancias que han dado lugar a su escritura, para de ahí deducir de qué manera han influido en su concepción y cuáles han sido las intervenciones que los lectores posteriores han ido operando sobre el texto. Ahora bien, las conclusiones a que se llega revierten, a su vez, en una interpretación de la historia del momento en que ha sido escrito. La labor filológica pretende en primer término la comprensión del texto y, a través de ella, contribuir a la mejor comprensión de las épocas a las que el texto ha pertenecido: la de su creación y las subsiguientes épocas de recepción. Esquivar el escollo que supone este círculo vicioso es difícil, pero no imposible. Es necesario distinguir lo que es una ratificación de datos 
adquiridos por otros medios, establecer una clara separación entre la parcela de una información directa que responde a la realidad y la que es resultado del género del texto; el método filológico sirve para obtener datos fiables sobre las intenciones del escritor recurriendo al análisis de los usos no conscientes de la lengua.

No son éstos únicamente los riesgos que corre el filólogo al estudiar un texto. Hay que tener siempre presente la necesidad de no trasladar nuestra mentalidad actual sobre épocas de las que nos separan siglos, si no queremos perder para siempre la riqueza de una cultura, que es el resultado de una superposición selectiva, más que de una prolongación de formas y conocimientos. Por ejemplo, la filología enseña a no caer en la tentación de trazar semejanzas entre nombres de instituciones, cuya forma se conserva, pero recubriendo realidades distintas, como no podía ser menos. Si nuestra democracia actual no debe compararse con la de hace un siglo, mucho menos debe establecerse su equiparación con la democracia griega, aunque sólo fuera por el hecho de que la democracia en un pueblo donde la esclavitud es asumida como natural no puede responder a un esquema equivalente. La filología exige el máximo respeto a la cultura de cada momento, aunque el respeto no siempre signifique exaltación; muchas veces hay que aceptar las deficiencias y los horrores de épocas que, al fin y al cabo, son nuestras, dado que de ellas procedemos, aunque pretendamos despreciarlas y, en ocasiones, olvidarlas.

Sólo cuando se conocen los riesgos se puede avanzar en el estudio de los textos, con el fin de aportar con esta labor algo, por mínimo que sea, a la comprensión de un autor dentro de una época, a una época a través de un autor. Porque la filología introduce asimismo al especialista en el fascinante mundo de la historia de la recepción, de la historia de los textos, tan vinculada a la historia de las formas de pensamiento. Para ello cuenta con dos instrumentos básicos: el conocimiento profundo de la lengua y de las formas literarias a que ha dado lugar esa lengua, ambas acompañadas de su historia. Es un error pensar que se puede trabajar sobre un texto latino de la Edad Media sin conocer el proceso previo a la configuración que ha adoptado. Por poner un ejemplo evidente: no se debe abordar el estudio de las comedias de la monja Hrosvitha sin conocer perfectamente la comedia romana anterior, porque fue esa comedia la que Hrosvitha leyó y modificó con el fin de adaptarla a la finalidad que perseguía. 
Pero tampoco pueden dejarse de lado las formas de teatro coetáneas a Hrosvitha, porque la autora, aunque conscientemente se atiene al camino seguido por Terencio, pertenece a una época cuyas realidades literarias le han venido impuestas de manera natural. Y lo que es válido para la forma literaria es válido para la lengua y la forma en que la autora se expresa: inevitable conocimiento del latín terenciano, pero inevitable también conocimiento del latín del siglo XII. No son estos requisitos exclusivos para emprender el trabajo filológico sobre textos de la Antigüedad Clásica o la Edad Media; lo dicho cabría aplicarlo a Shakespeare o a Cervantes, con una complicación añadida, que el lenguaje literario manejado por éstos era doble: latino y vernáculo.

\section{Un texto: las Etimologías de Isidoro de Sevilla}

De lo expuesto hasta aquí, creo que es fácil deducir que la filología, a diferencia de la crítica literaria, no sólo se ocupa de textos que entran en la por nosotros llamada literatura. Este es un punto de partida especialmente válido para las literaturas antiguas, cuyos especialistas se ven obligados a asumir la tarea de ocuparse de las llamadas literaturas técnicas, denominación cuyo referente es ambiguo. ${ }^{9}$ Los textos no literarios, en su sentido actual, tanto o más que los literarios, sirven a la filología para alcanzar sus fines.

Suponiendo que todo lo que acabo de decir cumple con el requisito exigido por la tradición, si no haciendo una defensa de mi profesión, sí intentando explicar su existencia, creo que el hecho de que una tradición se mantiene exclusivamente sobre la base de una forma externa me permite introducir una variante, muy relacionada con lo anterior: hablar de un texto. Como aconseja Séneca, un escrito debe contar con una parte en la que se expongan las normas que se van a exponer, seguidas de una ejemplificación que las haga más comprensibles.

En lo que me resta de tiempo, quisiera ejemplificar en las Etimologías de Isidoro de Sevilla las posibilidades que a un filólogo le ofrece un texto. Se trata de un texto no literario, quizá desconocido para la mayor parte de la gente e injustamente considerado por parte de aquella minoría que lo conoce, aunque sólo sea por referencias indirectas. 
Conocemos bastantes datos sobre su autor. Isidoro fue obispo de Sevilla en época visigoda, intervino activamente en la política de su tiempo; sus obras se escalonan, aproximadamente, desde el 615 al 636, fecha de su muerte, es decir, están escritas con posterioridad a la conversión de este pueblo al catolicismo en el reinado de Recaredo. Los antiguos territorios del Imperio Romano de Occidente comienzan a redefinir sus respectivas fronteras de acuerdo con los distintos pueblos que los han ido ocupando desde el siglo II d.C. y Bizancio, capital del imperio oriental, ha intentado por última vez rehacer una unidad imperial ya perdida para siempre.

Las dos últimas grandes figuras de escritores, aunque bajo distintos ángulos, Gregorio de Tours y Gregorio Magno, papa han muerto a finales del siglo VI (594) y comienzos del VII (604), respectivamente.

En este confuso mundo en gestación, al que comienza a resultarle ajena la lengua en que está escrito el total de su tradición político-cultural, desde la literatura de entretenimiento a las leyes, y que no posee todavía una alternativa propia, la presencia del reino visigodo puede considerarse un a modo de islote. Durante la primera mitad del siglo VII se produce la unificación de la península bajo la monarquía visigoda; desaparece el enclave bizantino del sur de la península. La jerarquía eclesiástica alcanza una influencia política difícilmente concebible: los concilios se nos muestran como parte fundamental del sistema político. En torno a los centros eclesiásticos se crean círculos de gente interesada en la difusión y cultivo de la cultura: Leandro e Isidoro de Sevilla, hermanos y obispos de la ciudad hispalense, Ildefonso de Toledo, Braulio y Tajón, obispos de Zaragoza. Nobleza y monarcas participan de ese interés y, en algunos casos, lo protegen. Dentro de este panorama, el personaje de Isidoro de Sevilla centra la atención como representante excepcional de una época y de una zona del antiguo imperio: Hispania.

Las Etimologías es una de sus obras, la más importante y, desde luego, la más conocida. Cuando se menciona y se estudia, se hace bajo el nombre de "Enciclopedia" y, en algunos casos, recibe un complemento y pasa a ser la "Enciclopedia de la Edad Media". Todos sabemos que disponer de un término definidor para un objeto contribuye a transmitir la sensación de que lo conocemos. De modo que 
las Etimologías pasan por ser una enciclopedia antigua, o anticuada, basada - como su nombre indica - en el conocimiento del objeto proporcionado por la etimología de la palabra que lo designa. Si pensamos que las etimologías manejadas en el siglo VII d.C. distan mucho de corresponderse con la idea de etimología que actualmente tienen los lingüistas, una apreciación de la obra resultante de una mentalidad actual, conduce a rechazar las Etimologías como una enciclopedia inservible desde el punto de vista de su contenido, sin ningún valor científico, risible por el tipo de etimologías aceptadas y sin valor desde el punto de vista literario, puesto que la prosa corresponde a un periodo muy tardío de la lengua latina y el carácter utilitario que el autor ha intentado conferirle le ha llevado a la elección de un lenguaje plano. Tal vez algún ejemplo sirve para comprender cual es el tipo de etimologías que recuerda el lector. Dice Isidoro (11.2.35): Cadauer autem est, si insepultum est. Nam cadauer nominatum a cadendo, quia iam stare non potest, es decir: "Es cadáver si esta sin sepultar y recibe el nombre de cadáver porque se cae, porque ya no puede mantenerse en pie". ${ }^{10}$

¿Qué interés puede tener el estudio de un texto así? Empezaré por exponer brevemente el de alcance más general que, por ello precisamente, explica el resto: llevar a cuestionarse sobre la inexactitud de muchas ideas admitidas. Es un ejercicio que practicamos poco, pero que conduce a resultados positivos. En primer lugar, nos lleva a preguntarnos qué entendemos por enciclopedia, qué ha llevado a conocer esta obra bajo esa denominación. Una suma de saberes, pero, y esto es fundamental, ¿dispuestos cómo dentro del todo? ¿por orden alfabético, tal como es habitual actualmente? o ¿estamos ante una serie de manuales yuxtapuesta, tal como se entendía todavía en la primera mitad del siglo XX?

En el siglo VII la organización por orden alfabético apenas es utilizada. Si es por materias o por temas, ¿cuáles son las materias consideradas básicas en el siglo VII, llegado el momento de compilar una enciclopedia? Y, yendo un poco más allá, ¿cuál es la organización interna dada a cada una de esas materias en su interrelación? Ya puestos a preguntarse, las cuestiones se encadenan, ¿son materias tradicionales en su momento o nuevas? ¿ofrece nuestro autor alguna originalidad en su tratamiento?

Estamos sólo ante la primera etapa de una práctica filológica: el planteamiento ante un texto de toda clase de preguntas. 
Un segundo tipo de cuestiones, no necesariamente posteriores, nos lleva a plantearnos cuáles fueron las razones que pudieron dar origen a una obra de este tipo. Y en conexión necesaria con esta cuestión, cuáles fueron las causas que hicieron de ella un instrumento necesario a tantos siglos de cultura. Es doble el interés que ofrece para el filólogo: analizar el porqué de este éxito y estudiar su historia, de la que únicamente conoce datos dispersos.

Las Etimologías constituyen, tal como las conocemos actualmente, una voluminosa obra dividida en 20 libros, cuya idea central parece clara: compendio de saberes. ${ }^{11}$ Suele hablarse de ella como filón de todo conocimiento sacro y profano, definición que naturalmente hay que referir a la época. Su eje, la línea directriz que podría explicar la organización que se ha dado al conjunto, cuál era la jerarquización de los conocimientos, cuál la idea de jerarquía dentro de cada grupo, eso sigue sometido a discusión. Si se lograra delimitar ese hilo conductor, podríamos concluir cuál era la idea que del conocimiento en su totalidad tenía Isidoro y, por extensión, cómo fue percibida por sus coetáneos y cómo por los hombres de los siguientes siglos. Y, para empezar: cuál fue su forma original, si es que es posible averiguarlo.

Un texto del siglo VII, antes de llegar a nosotros, ha pasado por múltiples vicisitudes difíciles de reconstruir. Un texto como el de Isidoro ha sido objeto, desde el principio, de numerosas copias, de copias de copias y copias de copias de copias. Todo centro de cultura deseaba poseer un ejemplar o varios, sin contar con las pequeñas bibliotecas personales. Los copistas cometen errores, revisan, amplían, contaminan cuando tienen a la vista más de un modelo para copiar. El texto se concibe durante siglos como patrimonio de cada uno de los lectores que lo maneja, aprende o reflexiona sobre él. Las reflexiones de un lector se incorporan algunas veces al texto. El texto se reduce, se selecciona, se amplía; se comenta.

Nos han llegado cientos de ejemplares manuscritos de las Etimologías, que van desde el siglo VIII al siglo XV. Ninguno de ellos, casi con seguridad, se corresponde con el escrito o los escritos por Isidoro, porque también Isidoro pudo dar más de una versión del texto. Braulio de Zaragoza reconoce haber modificado el original isidoriano antes de editarlo, haberle dado la distribución en 20 libros que ahora conocemos. 
Los textos clásicos consagrados cuentan con una historia debida a filólogos anteriores, lo bastante fiable, como para poder trabajar sobre ellos sin necesidad de rehacerla: manuscritos y transmisión cuentan con estudios que garantizan el texto que poseemos. En el caso de Isidoro y, en general, de los autores tardíos que han sido soslayados hasta hace poco relativamente, en virtud de su escaso valor literario e informativo, el trabajo que lleva a la fijación del texto es previo e imprescindible. No es trabajo de una sola persona, sino de un equipo y de muchos años y sólo hace unos tres decenios se ha emprendido la tarea, encargando a un grupo de 20 estudiosos europeos - entre los cuales nos contamos 3 universitarios salmantinos - la edición de cada uno de los 20 libros de las Etimologías, de acuerdo con sus especialidades. Esos cientos de manuscritos de los que he hablado, dispersos por las bibliotecas europeas, sobre todo, siguen encerrando claves que posibiliten la comprensión de cuál fue la vida del texto, cuáles sus lectores y la razón de su éxito a través de circunstancias tan diferentes.

En este tipo de obras, de carácter pedagógico, la transmisión del texto casi de manera necesaria debe partir de un estudio de las condiciones de edición, punto inseparable del análisis del texto como obra en su conjunto. Sobre todo, tratándose como se trata, de una obra en la que los conocimientos se suman, no se entretejen, y en la que cabe añadir, cortar, seleccionar y ofrecer aisladamente.

Generalmente, para la edición de una obra que cuenta con la cantidad de manuscritos con que cuentan las Etimologías, el editor suele proceder a una selección que, por principio, atiende al criterio de antigüedad. Se entiende que cuanto mas próximos al original mas posibilidades existen de que el texto que manejamos no se haya deteriorado demasiado. La reducción en nuestro caso puede alcanzar el número aproximado de 30 manuscritos, todos pertenecientes a los siglos VIII y IX. Del estudio de esta selección no sólo se obtiene una versión más o menos próxima a lo que pudo ser el original, sino una idea de cuál pudo ser la intención de su autor al componer la obra.

Para que se vea la importancia que cualquier detalle tiene para restituir las ideas de Isidoro, que es probable que responda a las ideas de su época, voy a recurrir a una cuestión que afecta exclusivamente a la división en libros. La tradición manuscrita nos ofrece el libro XI dividido unas veces en 4 capítulos (el hombre como ser físico y sus 
variantes anormales) y otras en 11 en la que los 4 anteriores se añaden los distintos géneros animales. La división en 11 capítulos obliga a una observación presente al comienzo del libro siguiente advirtiendo que los capítulos de ese libro se encontrarán en el libro anterior. Pues bien, de la conclusión a que lleguemos tras del estudio de esta tradición depende que nuestra idea de la concepción del mundo isidoriano se incline en un sentido o en otro. Si pensamos que sólo tenia 4, el hombre en intención de Isidoro ocupa un lugar especial dentro de los seres animados. Si tenía 11 capítulos, entonces el hombre, para Isidoro, comparte categoría con el resto de los seres vivos.

La mayoría de los códices introducen antes de la obra una parte previa consistente en un intercambio de cartas entre Braulio e Isidoro, cinco, algunas de ellas relativas a las Etimologías. Aunque no se transmite junto con las Etimologías, contamos con una biografía de Isidoro debida a Braulio, en donde, entre las obras que le atribuye, habla de las Etimologías y de su intervención sobre ellas. La conclusión es que las Etimologías fueron conocidas en distintas versiones, cuya extensión y contenido no se conoce; que Braulio intervino en la edición dividiendo la obra en libros, división ajena a su autor. En resumen que la obra, tal como la conocemos, no responde exactamente a la versión isidoriana y que no debemos hablar de versión sino de versiones. Apuntan a restos de antiguas versiones la ausencia del libro de medicina en algunos códices; el distinto orden que siguen, en los distintos manuscritos, los diez primeros libros; la agrupación en tres partes de estos mismos libros; la concepción en dos partes de la obra completa. Estos datos son indicadores de más cosas de las aparentes, orientan en otra dirección la intención de Isidoro al componer las Etimologías.

Las tres partes en que se ofrecían los diez primeros libros, tal vez sin el libro sobre medicina en un primer momento, nos ofrecen una agrupación curiosa: un primer grupo que incluye breves manuales de las siete artes liberales: gramática, retórica y dialéctica/lógica (triuium) y aritmética, geometría, música y astronomía (quadriuium). Son manuales en donde se recurre al método tradicional de la acumulación de normas, en el caso de los tres primeros, o en los que prima la descripción del objeto - los correspondientes a la parte del quadriuium.

Un segundo grupo contiene un apartado De legibus, otro De temporibus, seguidos de un libro De nouo et ueteri testamento. De 
ecclesiasticis officiis. En el primero no se pretende ofrecer un pequeño código en el que se registren normas que deben ser acatadas, sino que se habla de quiénes fueron los primeros legisladores, definen tipos de derecho, tipos de castigo posibles etc. El apartado que recibe el nombre De temporibus incluye una serie de datos sobre lo que se entiende por día, mes, año etc. y termina con una pequeña historia de la humanidad desde Adán, distribuida en seis edades. Hasta aquí nada relacionado con la Iglesia, si exceptuamos alguna alusión suelta a la primacía de los personajes bíblicos en el descubrimiento y práctica de alguna de las materias.

A los anteriores sigue un apartado cuya materia es religiosa: es curioso que la primera sección de este apartado, naturalmente descriptiva, esté dedicada a la Biblia, al Antiguo y Nuevo Testamento. Junto a los libros de leyes, los libros por los que sirven de pauta para el comportamiento de la sociedad cristiana. En cuanto a la naturaleza de la segunda sección del apartado, es normativo-informativa: la celebración de la Pascua, las ceremonias y festividades eclesiásticas, o sea, normas internas a la Iglesia. Hay una norma laica, que fija el cómputo del tiempo de acuerdo con medidas físicas y registra el paso del tiempo de acuerdo con acontecimientos políticos, en todo caso, temporales. La Iglesia atiende a otro tipo de criterios, basados todos en acontecimientos de dimensión sobrenatural o simbólica. Ambas secciones corren en paralelo, pues, con las dos secciones del libro anterior: mundos paralelos y complementarios que se dan la mano.

El cristianismo con Isidoro incorpora definitivamente los instrumentos básicos creados por la sociedad laica: artes liberales y en su caso medicina, igual en ambas sociedades. Hace también suyas normas indispensables para la necesaria convivencia: leyes, distribución del tiempo y crónica de acontecimientos políticos, pero añadiéndoles en correspondencia las "leyes" exclusivamente cristianas y el modo de determinar los acontecimientos que para el cristianismo son cruciales y que imponen un tipo de cómputo específico.

Hasta aquí normas, informaciones, descripciones sobre los instrumentos que posee el hombre para organizarse dentro de una sociedad cristiana, que incorpora siempre sus aspectos laicos.

Por último, un tercer apartado que se inicia con los nombres de dios. Bajo este criterio, Isidoro introduce la parte más original de 
toda la obra en su concepción, que se adecua con mucha mayor fidelidad al procedimiento etimológico. Todos los elementos que constituyen la sociedad divina y humana encuentran su lugar por medio de su definición, definición que llega casi siempre a través de la etimología: dios se define por sus nombres; ciudadanos, cargos políticos, cargos militares encuentran su lugar sucesivamente y en contacto con el resto de individuos que pertenecen a la misma comunidad: Iglesia, Ciudad, Estado, Familia e Individuo. Isidoro ofrece una imagen unitaria del mundo, en la que las dos ciudades - la humana y la divina - aparecen unificadas, inseparables y en ellas el hombre, en sí mismo, ocupa un lugar de importancia relevante, ya que todo un libro, aquel con que se cierra esta primera parte, está dedicado enteramente al hombre definido por sus cualidades.

Lo que resta de la Etimologías, la segunda parte, es una suma de conocimientos que parten del hombre como ser humano y llegan a cualquiera de los elementos que rodean su vida o en los que ésta se desenvuelve: el universo físico en todos sus componentes y el universo que él mismo ha creado y del que es responsable: desde la guerra hasta los utensilios domésticos. La parte que propiamente podríamos reconocer como enciclopedia.

Muchas cuestiones quedan pendientes. La primera ya ha quedado expuesta: ¿realmente esa organización que hemos reconstruido responde a Isidoro o a Braulio? Si el texto que poseemos es próximo al de Isidoro, ¿esta concepción global de la obra ha sido concebida previamente por Isidoro o es el resultado del azar? ¿Fue la reflexión generada a medida que las partes iban surgiendo la que llevó al final a organizar el material? La diferencia es importante si pensamos en analizar el método de trabajo del autor o emitir conjeturas sobre la finalidad o función otorgada por Isidoro a las Etimologías.

Una segunda fase o estadio en el estudio de esta obra plantea un problema idéntico, pero con un desplazamiento de protagonista. Aceptando que la concepción de las Etimologías se ajuste a lo dicho, ¿cómo la vieron las épocas siguientes, cuál fue la lectura que los hombres cultos de cada época hicieron de este compendio de saberes? Las Etimologías han sido utilizadas como soporte de nuevas informaciones y visiones distintas, han sido saqueadas en busca de datos válidos para ser insertados en otras enciclopedias, de ellas proceden una gran cantidad 
de palabras (con las correspondientes definiciones) de diccionarios y glosarios. Unas veces el autor que lo utiliza lo cita, otras veces no.

Pero tan importante como estas incorporaciones o saqueos, depende de cómo se mire, son los cambios del texto derivados de lectores anónimos: copistas y usuarios. El texto pertenece a todos, incluso al copista anónimo que añade explicaciones o pequeñas ampliaciones en los márgenes del códice. Los lectores de la Edad Media han sentido necesidad de modificar, seleccionar, añadir información sobre la parte relativa a la formación básica del hombre cristiano. Se prolonga la crónica, se amplía la medicina, la música, la astronomía, se edita aisladamente la gramática, se prescinde de partes de la retórica etc. En cualquiera de estos casos estamos gozando del privilegio de asistir a la acomodación del universo isidoriano a los cambios de mentalidad de un grupo u otro, al predominio o superior valoración de una disciplina u otra. Muchas veces es posible localizar lugares de copia, siempre lo es fijar el momento de copia. Se dibuja así un mapa de intereses, se aprecia qué elementos del mosaico inicial, configurado según la iniciativa de un autor, han servido de pauta para encauzar y representar nuevos intereses de épocas muy distintas.

Hemos llegado al punto de que partimos. Las enciclopedias, como toda creación humana, llevan la impronta y marcan, a su vez, con su impronta los siglos que asisten a su aparición. Isidoro parece haber concebido la enciclopedia como reflejo de la sociedad y del mundo por él conocido. De manera subliminar el lector se impregna y hace suya esa visión. Los lectores de siglos posteriores perciben las Etimologías a su manera, desglosada en piezas, incluso en palabras; añaden, completan, eliminan, recortan y seleccionan lo que a cada uno interesa. Basta ver los Specula de Vincent de Beauvais (c. 1190c. 1264), en el siglo XIII, una voluminosa enciclopedia, para darse cuenta de la sustitución de la idea central. Vincent de Beauvais en su Speculum maius musestra el mundo en lo que para él son sus manifestaciones básicas. Las tres partes en que esta concebida: Speculum naturales, Speculum doctrinale y Speculum historiale, nos hablan de las ideas que subyacen a su redacción. La primera parte, partiendo del Génesis, va exponiendo a lo largo de 32 libros información sobre todo lo creado, en el orden seguido por el relato bíblico y comenzando por el Creador: la luz, el cielo y sus partes, las aguas... hasta llegar al hombre. La segunda, que comienza con la caida del hombre, se ex- 
tiende ampliamente en la exposición de los medios de que el hombre se vale en la tierra para alcanzar su liberación del primer pecado; son estos la lengua, la gramática, la lógica etc. Consta de 17 libros. Por ultimo, la tercera parte, que contiene 31 libros, esta dedicada a la historia de la humanidad, desde Adán hasta el ano 1250.

Los diccionarios son, hasta cierto punto, una variante de la enciclopedia: las palabras de una lengua sirven para expresar parcialmente aspectos del mundo que la habla. Ha habido intentos de ordenar temáticamente los diccionarios, en un afán de hacer de ellos un trasunto de la visión del mundo.

Pero el orden alfabético se ha impuesto. Los llamados ahora diccionarios enciclopédicos en nada recuerdan a la gran enciclopedia isidoriana. Cargados de información, necesitada constantemente de revisión, cada entrada remite a otra u otras que, aunque en intención procuran encerrar pequeñas parcelas del universo, acrecientan la sensación de dispersión, favorecida por la progresiva especialización. Las Etimologías pertenecen al pasado como instrumento científico, pero pertenecen a la actualidad como objeto en manos de los científicos. Sometidas a un estudio filológico, pueden ayudarnos a comprender de dónde procedemos, cuáles fueron las raíces ideológicas que, partiendo de Hispania y extendiéndose por el resto de Europa, contribuyeron a configurar al hombre de un periodo que cada día se revela como más determinante: la Edad Media.

Imitando a un humanista italiano no muy conocido, Lapo de Castigliochio, quisiera terminar con las palabras con que él lo hacía en su introducción al curso de retórica en la Universidad de Bolonia (c. 1435$)^{12}$ :

(...) animaduerti in huius modi legendi initiis non tam praecipiendi utilitatem quam aurium uoluptatem et delectationem quaeri solere, ad haec plurimos in unoquoque doctrinae genere eruditissimos uiros hunc in locum non discendi aliquid, sed mei potius ornandi causa conuenisse, quibus praesentibus si quam artem aut facultatem docere aggressus essem, ueritus equidem sum ne, quod turpissimum est, apud eos arrogantiae et temeritatis uituperationem subirem, atque illud uerissime in me dari posset quod tritum est attrito sermone prouerbium: sus athenan didaskei, id est, 'sus Mineruam docet'

[(...) soy consciente de que en los comienzos de este tipo de lecturas no suele buscarse tanto la utilidad como el placer y el deleite del oído, de que en este 
acto se han reunido hombres especializados en todas las materias existentes no tanto para aprender como para acompañarme y arroparme. Si yo, en su presencia, hubiese intentado enseñar cualquier disciplina o especialidad, me temo sin duda alguna que incurriría en la crítica de arrogante y osado, y se me podría aplicar el conocidísimo dicho popular: "el cerdo enseña a Minerva"].

La conciencia ante un hecho no equivale a capacidad para solucionarlo en el sentido que uno pretende. Es verdad que no he pretendido otra cosa que sacar de la incomprensión, tal vez por mí sospechada, que no real, a esa apasionante desconocida que es la filología. Podría haberse hecho mejor, pero no con mayor convencimiento y entusiasmo. Acepto que ambos están relacionados con mi amor a mi profesión, pero existe una relación mucho más estrecha con su valor real. La filología enseña otro método de aproximarse al pasado, de fijar el recuerdo de mundos que fueron y siguen siendo a través de nosotros. Entre mis sueños, por otra parte escasos, figura la imagen de una filología que dentro de siglos sea capaz de leernos, interpretarnos y hacer comprender a los imaginados habitantes de ese mundo futuro, que nuestra existencia, nuestras creaciones y nuestro trabajo forman parte de su realidad. Añadir al sueño que ese recuerdo no inspire rechazo, sino satisfacción es demasiado. Seamos modestos.

\section{Recebido em outubro de 2004 e aprovado em fevereiro de 2005.}

\section{Notas}

1. Especialmente conocida es el Panepistemon de Poliziano, praelectio al curso que Angelo Poliziano ofreció sobre la Etica a Nicómaco de Aristóteles en 1491.

2. Una anécdota narrada por Nebrija en su Apologia al Cardenal Cisneros recoge con bastante exactitud cuál pudo ser la causa del abandono. Discursos inaugurales y repetitiones solían declamarse, no leerse. Nebrija justifica su lectura para dar a entender que su intervención es resultado de una preparación previa y, a propósito de ello, cuenta el asombro del Papa ante el hecho de que los catedráticos de Universidad en España estén obligados a una repetitio anual y la ausencia de ediciones impresas que lo demuestren.

3. En una Bula de Bonifacio VIII se fija esa fecha como inicial y S. Pedro y S. Pablo, 29 de junio, como final del curso académico. Véase A. Mercati, "Rara edizione di una bola de Bonifacio VIII all'Università di Roma", Miscellanea bibliograqfica in memeoria di Don Tomasso Accurti, Edizioni di Storia e Letteratura, Roma, 1947, p. 141-148.

4. Raras veces el total de las enseñanzas resultaba de la complementariedad entre dos sedes, como fue el caso de Florencia y Pisa por un tiempo. La primera era sede de la especialidad

Educ. Soc., Campinas, vol. 26, n. 90, p. 149-170, Jan./Abr. 2005

Disponível em <http://www.cedes.unicamp.br> 
en artes, la segunda de medicina, derecho y teología. Sobre los tópicos y su disposición en el discurso inaugural de curso, tenemos el estudio de M. Campanelli, "L'oratio e il 'genere' delle orazioni inaugurali dell'anno accademico" en Lorenzo Valla. Orazione per l'inaugurazione dell'anno accademico 1455-1456, a cura de Silvia Rizzo, Roma, Roma nel Rinascimento, 1994, p. 25-60.

5. Cuando se habla de la presencia de una laus litterarum en las orationes inaugurales exige alguna aclaración. Hay que entender litterae como equivalente de artes, es decir, de las materias que constituían el ciclo de las siete artes liberales tradicionales, a las que se sumaba el elogio de las otras especialidades o facultates: medicina, derecho y teología. Por otra parte, los discursos de inauguración de curso no se limitaban a esta laus, sino que incluían, como queda dicho, otra serie de motivos. Por esta razón, me parece conveniente distinguir entre laudes litterarum, que encuentran su lugar y su función dentro de distintos géneros, y dar el nombre de orationes inaugurales a estos discursos específicos.

6. De la aparente contradicción que revela un análisis del discurso de Lope de Herrera nos habla F. Rico en "Laudes Litterarum: humanisme et dignité de l'homme dans l'Espagne de la Renaissance”, L'humanisme dans les lettres espagnoles (ed. A. Redondo), París, Vrin, 1979, p. 31-50.

7. Sobre este punto en concreto, puede verse al artículo de J. Alcina, "Poliziano y lo elogios de las letras en España (1500-1540)", Humanistica Lovaniensia, 51, 1978, p. 198-222. Tomo de él la parte que se refiere al discurso de Juan Pérez.

8. Es bien conocida la justificación que Nebrija hace de la labor del grammaticus. Éste no pretende invadir el terreno de astrónomos, médicos, juristas o teólogos. Tal como dice en su Iuris ciuilis Lexicon, sin salirse de sus competencias, hace incursiones en otras disciplinas. Pero lo hace exclusivamente desde su condición de grammaticus, no de especialista en la materia: Sed inueni uiam qua me ab illorum inuidia exonerarem atque illos placatos dimitterem, si dixero me de uocabulis ad ius ciuile pertinentibus non tamquam iuris studiosus, sed tamquam grammaticus disputare".

9. El apelativo "técnicas" es de nuestra época. En latín no se distingue demasiado bien entre texto literario y no literario; el ejemplo que puede ser más comprensible y que siempre se utiliza es el de la historia o la filosofía, literatura para ellos, no literatura para nosotros. Por otro lado, no hay que olvidar que el estudio de la Antigüedad Clásica recayó desde muy pronto en manos de los filólogos, para quienes esa distinción resulta ineficaz.

10. En este caso en concreto hay que advertir que la derivación de cado es correcta; lo que da un cariz propio es la justificación, elemento imprescindible para nuestro autor.

11. Isidori Hispalensis episcopi Etymologiarum siue Originum libri xx, ed. W. C. Lindsay, Oxford, Oxford University Press, 1911.

12. "Lapi Casteliunculi oratio Bononiae habita in suo legendi initio ad scolares et alios tunc ibi praesentes", en K. Müllner, Reden und Briefe italienischer Humanisten, Wien, 1899, p. 129-139. 